\title{
BIBLIOGRAFIA COMENTADA SOBRE A ASSISTÊNCIA AO PARTO NO BRASIL (1972-2002)
}

MARIA LUCIA MOTT (Org.)

Centro Universitário Adventista

\begin{abstract}
Resumo: A organização desta bibliografia teve por objetivos: 1) divulgar trabalhos sobre a assistência ao parto no Brasil, produzidos em diferentes áreas de conhecimento (história, antropologia, enfermagem, medicina, assistência social, psicologia e sociologia); 2) colocar em contacto pesquisadores que trabalham o tema; 3) dar espaço para assuntos, abordagens e autores não contemplados no dossiê. Foram referenciados e resumidos 77 trabalhos (artigos, dissertações, teses, relatórios, cartilha), produzidos por cerca de 50 autores, publicados ou realizados entre 1972 e 2002.
\end{abstract}

Palavras-chave: assistência ao parto, bibliografia, Brasil (1972-2002).

Esta bibliografia tem dupla origem: deve-se, em primeiro lugar, à impossibilidade de o dossiê dar conta, em um único número da revista, dos vários enfoques e recortes sobre a assistência ao parto no Brasil. Em segundo, à multiplicação de pesquisas realizadas nas duas últimas décadas sobre o tema, muitas delas de conhecimento público bastante restrito apesar da qualidade, da importância das propostas e das informações levantadas.

Tornava-se, pois, necessário juntar essa produção multidisciplinar esparsa, colocando em circulação os trabalhos realizados nos diferentes estados brasileiros, por pesquisadores vinculados a centros de pesquisa e universidades, a grupos feministas e a organizações governamentais e não-governamentais.

O levantamento dos trabalhos foi realizado por meio da divulgação de um pedido feito na Internet (grupos de discussão, departamentos universitários, pesquisadores, etc.) para o envio das referências e dos respectivos resumos. Portanto, não foi feita uma pesquisa sistemática em bibliotecas, coleções de revistas, como usualmente são organizadas as bibliografias. A resposta foi muito boa: pesquisadores de várias áreas de conhecimento (história, antropologia, enfermagem, medicina, assistência social, psicologia e sociologia), utilizando distintas abordagens, e de diferentes áreas geográficas do país responderam imediatamente; outros enviaram indicações e resumos de trabalhos de terceiros. ${ }^{1}$ Vale destacar que a grande maioria dos resumos foi realizada pelos próprios autores; uma

Copyright $\odot 2002$ by Revista Estudos Feministas

1 Agradeço a Maria Alice Tsunechiro (MAT) e a Lucila Scavone (LS) a indicação de várias referências e a elaboração de resumos. Os resumos por elas elaborados e por mim (MLM) possuem as iniciais no final do texto. 
parte pequena foi feita por quem indicou a referência; e uma parte menor ainda resultou da transcrição de resumos previamente elaborados (em teses, periódicos, etc.).

Somaram-se, assim, 76 trabalhos (artigos, dissertações, teses, relatórios, cartilha), produzidos por cerca de 50 autores, publicados a partir de 1972. ${ }^{2}$

Deve ser mencionado que autores, títulos e recortes temáticos importantes, como por exemplo a mortalidade materna, em que não só questões sociais, mas também étnicoracias são consideradas, infelizmente não estão suficientemente contemplados, o que aponta para a necessidade da continuação deste trabalho.

1. BARBIN JR., Hélio. Parteiras tradicionais da floresta. Rio Branco: Ed. Poronga, 1998. Cartilha produzida pelo Projeto de Saúde Reprodutiva na Reserva Extrativista do Alto Juruá "Maria Esperança", com a finalidade de levar informações às parteiras e aos agentes de saúde sobre pré-natal, parto e puerpério, para atenderem as necessidades da população da Reserva. O projeto vem sendo realizado em parceria com as ONGs Associação dos Seringueiros e Agricultores da Reserva Extrativista do Alto Juruá (ASAREAJ) e Associação Saúde Sem Limites (SSL), com financiamento da Fundação MacArthur. Teve início em 1996, foi refinanciado (1999-2002) e atualmente está em fase de finalização.

2. BARRETO, Maria Renilda N. "A nova ética do nascimento na Bahia do século XIX". In: MOTTA, Alda Brito da et al (Org.). Um diálogo com Simone de Beouvoir e outras falas. Salvador: NEIM/UFBA, 2000. p. 325-333. O texto apresenta a discussão em torno da saúde e do corpo feminino em Salvador do século XIX. O locus do debate foi a Faculdade de Medicina da Bahia, e o interesse dos médicos pelo corpo da mulher estava revestido de idéias normatizadoras, associadas ao desdobramento da 'missão civilizadora' da nação brasileira. Assim, percebe-se a projeção de padrões para o comportamento feminino, quer no espaço doméstico, quer no do lazer ou no trabalho.

3. BARRETO, Maria Renilda N. "Corpo de mulher: a trajetória do desconhecido na Bahia do século XIX". In: MARTINS, Ana Paula Vosne (Org). História: questões e debates. Curitiba, v. 18 , n. 34 , p. 127-156, jan./jul. 2001. Entre outras questões, o texto aborda o papel desempenhado pelas comadres baianas, desde a gravidez até o batismo. Indica também elementos de permanência, principalmente em locais onde a população não é assistida pelos cuidados médicos ou prefere a manutenção dos costumes ancestrais.

4. BARRETO, Maria Renilda N. Nascer na Bahia do século XIX: Salvador (1832-1889). 2000. Dissertação (Mestrado) - Faculdade de Filosofia e Ciências Humanas, UFBA, Salvador. O texto discute a ação das parteiras e dos médicos, profissionais que atuaram na assistência ao parto e à parturiente na cidade de Salvador. Investiga o conflito deflagrado pelos doutores na construção de uma outra ética do nascimento pautada no cientificismo oitocentista, ao mesmo tempo que revela a manutenção das práticas populares envolvendo a gravidez, o nascimento e os cuidados no pós-parto.

5. BARRETO, Maria Renilda N. "Doenças de mulheres na Bahia do século XIX". In: ARAS, Lina Maria Brandão de et al. (Org.). Fazendo gênero na historiografia baiana. Salvador: NEIM/UFBA, 2001. p. 27-34. O texto discute as enfermidades que atingiram a cidade de Salvador, no século XIX, com ênfase nas doenças femininas. Através dos registros da Santa Casa de Misericórdia da Bahia, dos relatos de casos clínicos publicados na Gazeta

\footnotetext{
${ }^{2}$ Não foram incluídos trabalhos de divulgação sobre assistência ao parto (parto na água, guias para gestantes e casais, etc.), pois um dos objetivos da bibliografia foi o de divulgar trabalhos acadêmicos e de intervenção social, e colocar em contato pesquisadores do mesmo tema.
} 
Médica da Bahia e de outros documentos, procurou identificar quem eram as mulheres atendidas na Santa Casa, quais as doenças que as afligiam e como se processava o tratamento. Esse tratamento era clínico e paliativo, com emprego de purgativos, sudoríparos e ervas da flora local. Portanto, era comum a mulher optar pelos tratamentos ministrados pelas parteiras nas doenças do aparelho geniturinário feminino, pois muitas vezes as técnicas terapêuticas dos médicos eram semelhantes às usadas pelos 'charlatães' ou pelas 'indignas comadres'. Essa pesquisa está em andamento e se constitui no projeto de doutorado em curso, pela Fundação Oswaldo Cruz (RJ).

6. BARROSO, Iraci C. Saberes e práticas das parteiras tradicionais do Amapá: histórias e memórias. 2001. Dissertação (Mestrado) - Departamento de História, Instituto de Filosofia e Ciências Humanas, UNICAMP, Campinas. Essa dissertação apresenta um conjunto de saberes e práticas que compõem o ofício das parteiras tradicionais em quatro municípios do Amapá. Baseia-se nos relatos de 20 parteiras que contam suas experiências no atendimento ao parto natural, no tratamento da mulher, da criança e da comunidade, na zona rural e nas periferias urbanas. Após as indagações sobre a atual inserção das parteiras nas políticas públicas através do Projeto de Capacitação do Programa de Desenvolvimento Sustentável do Amapá, percebe-se que esta é mais uma forma de controle do ofício de parteira pelo Estado. Demonstra finalmente que a legalização e o reconhecimento do ofício dependem da vontade política dos que governam o Estado do Amapá.

7. BESSA, Lucineide F. Ação educativa: uma perspectiva para a humanização do parto? 2002. Tese (Doutorado) - Escola de Enfermagem de Ribeirão Preto, USP, Ribeirão Preto. O estudo é qualitativo e analisa as relações que a mulher estabelece entre a sua experiência no processo parturitivo e no processo educativo para o parto. Foram analisadas dez mulheres no período de gravidez, parto e pós-parto e observados acompanhantes e profissionais de saúde. Os resultados demonstram que as mulheres reconhecem condutas que humanizam e desumanizam a assistência e que são capazes de sugerir mudanças para fortalecer o cuidado de si próprias.

8. BESSA, Lucineide F. Condições de trabalho de parteiras: algumas características no contexto domiciliar rural. 1997 Dissertação (Mestrado) - Escola de Enfermagem, UFBA, Salvador. O estudo é de cunho qualitativo e dialético e analisa as condições de trabalho da parteira tradicional rural. Foram realizadas observações em 11 comunidades rurais e entrevistadas 20 parteiras. Os resultados demonstraram que as funções domésticas inerentes ao trabalho da mulher parteira e as relacionadas com o cuidado e o servir estão associadas à condição feminina e, portanto, são produto de uma construção histórica e social.

9. BONADIO, Isabel Cristina. "Ser tratada como gente": a vivência de mulheres atendidas no serviço de pré-natal de uma instituição filantrópica. 1996. Tese (Doutorado) - Escola de Enfermagem, USP, São Paulo. Esse estudo, de abordagem qualitativa, tem como referencial teórico a antropologia cultural e utiliza o método etnográfico de pesquisa. Teve por objetivo conhecer e compreender as necessidades, crenças e valores do cuidado pré-natal na visão e experiência vivenciada por mulheres grávidas atendidas no contexto do serviço de pré-natal de uma instituição filantrópica. A análise dos temas culturais identificados levou ao tema central - "ser tratada como gente" -, revelando que, na vivência das mulheres, os elementos mais significativos são representados pela interação efetiva ou pelo estabelecimento de vínculo de confiança entre elas e a enfermeira. (MAT)

10. BRANDÃO, Nadja S. Da tesoura ao bisturi: o ofício das parteiras (1897-1967). 1998. Dissertação (Mestrado) - Instituto de Filosofia e Ciências Humanas, PUCRS, Porto Alegre. 
Estudo sobre o cotidiano das parteiras em Porto Alegre e em algumas cidades do interior do Rio Grande do Sul. Baseou-se em depoimentos orais de 'curiosas' e parteiras formadas, além de documentação médica. Focalizou o Hospital Moinho de Vento e a Santa Casa, onde funcionaram os cursos de Partos e Obstetrícia, de Enfermagem Obstétrica e de Visitadora Sanitária. Aborda temas referentes ao trabalho das parteiras, à assistência ao parto, ao papel do Estado nas questões de saúde, à crescente importância do hospital e ao aumento de cesarianas em detrimento do parto normal. Aponta para o declínio da profissão de parteira, que é alijada do seu trabalho pelas pacientes, pelo hospital credenciado e pelo médico plantonista, financiados pelo Instituto Nacional de Previdência Social. (MLM)

11. BRENES, Correa Anayansi. "História da parturição no Brasil, século XIX". Cadernos de Saúde Pública, v. VII, n. 2, p. 135-149, abr./jun. 1991. A pesquisa tenta resgatar as particularidades da constituição da arte obstétrica no Brasil, no século XIX, a partir da leitura das teses médicas produzidas no período na Escola de Medicina e Cirurgia no Rio de Janeiro. A entrada dos médicos - parteiros nesta prática - inaugura não só o esquadrinhamento do corpo feminino, como também a produção de um saber anatômico e fisiológico da mulher, a partir do olhar masculino.

12. BRENES, Correa Anayansi. "Nascimento e declínio da escola de parteiras diplomadas francesas: 1802-1877". Revista Médica de Minas Gerais, v. 9, n. 1, p 39-45, jan./mar. 1999. Reconstrução da história da Escola do Parto em Paris ao longo do século XIX, descrevendo em detalhes a formação profissional das alunas sages-femmes, a dinâmica do curso, os recursos e os possíveis entraves da época. Constam quatro imagens da época.

13. BRENES, Correa Anayansi. Um olhar brasileiro sobre o caso de Paris: o conflito parteiras \& parteiros e seus desdobramentos no Rio de Janeiro, século XIX. 1996. Tese (Doutorado) - Universidade Federal Fluminense, Niterói. Hipótese principal: seria a falta de conhecimento das parteiras a causa do atraso da profissão? Revisão de autores franceses contemporâneos. Extensa pesquisa realizada na França, dando-se destaque à Escola de Parto, criada em Paris, em 1802, e aos desdobramentos desta no projeto do Rio de Janeiro, no século XIX.

14. CARVALHO, Maria Luiza M. A participação do pai no nascimento da criança: as famílias e os desafios institucionais em uma maternidade pública. 2001. Dissertação (Mestrado) - Instituto de Psicologia, UFRJ, Rio de Janeiro. A participação dos pais no nascimento possibilita suporte psicossocial à gestante, compartilhamento da experiência pelo casal e formação de vínculos pais-bebês. Buscou-se conhecer o impacto dessa experiência entre os pais em uma maternidade pública no Rio de Janeiro através de uma pesquisa etnográfica. Essa prática sofreu interferência das resistências institucionais; das motivações das mães e dos pais; das representações sociais sobre parto e a paternidade; e da exclusão dos pais nos serviços de saúde reprodutiva e pediátrica. 0 estudo aponta a necessidade de políticas públicas específicas para a inserção dos homens nos serviços de saúde reprodutiva e pediátrica.

15. COSTA, Teresinha M. da. "Mortalidade materna em Juiz de Fora: uma realidade que não pode ser mais ocultada". In: BRANDÃO, Elaine R. (Org.). Saúde, direitos reprodutivos e cidadania. Juiz de Fora: Editora da UFJF, 2000. p. 9-26. O artigo discute a mortalidade materna no município, dando ênfase ao trabalho desenvolvido desde 1996 pelos Comitês de Mortalidade Materna, regional e municipal. (MLM)

16. DEL PRIORE, Mary. "A maternidade da mulher escrava". Estudos CEDHAL/USP, n. 4, 1989. Ensaio seguido de transcrição de documento setecentista, encontrado na Biblioteca de Lisboa, escrito pelo médico pernambucano Francisco Nunes. 
17. DEL PRIORE, Mary. "Magia e medicina na Colônia: o corpo feminino". In: DEL PRIORE, Mary. (Org). História das mulheres no Brasil. São Paulo: Contexto, 1997. p. 78-114. Capítulo sobre os problemas médicos que envolviam a sexualidade e a reprodução no passado, com especial atenção para o papel da mulher como portadora de saberes sobre o seu próprio corpo.

18. DEL PRIORE, Mary. Ao sul do corpo: condição feminina, maternidades e mentalidades no Brasil Colônia. Rio de Janeiro: José Olympio; Brasília: EDUNB, 1993. A autora analisa o universo feminino no Brasil no período colonial, com destaque para a maternidade dentro e fora da família, a sexualidade e os discursos de médicos, teólogos, moralistas e confessores sobre a mulher. O quarto capítulo -"Mentalidades em torno do parto" apresenta as práticas e os saberes das parteiras e dos médicos referentes à parturição.

19. DINIZ, C. Simone G. Assistência ao parto e relações de gênero: elementos para uma releitura médico-social. 1997. Dissertação (Mestrado) - Faculdade de Medicina, USP, São Paulo. O estudo busca enriquecer a compreensão das contradições técnicas e da chamada 'desumanização' das atuais práticas obstétricas no Brasil. Partindo do reconhecimento de que as práticas de saúde são socialmente construídas, analisa os relatos das práticas de assistência ao parto em diversos contextos históricos (Antigüidade clássica, ldade Média e Renascimento, advento da ldade Moderna e início do século XX no Brasil), e como essa assistência se expressa na construção do feminino, do masculino e da parturição.

20. DINIZ, C. Simone G. Entre a técnica e os direitos humanos:-limites e possibilidades das propostas de humanização do parto. 2001. Tese (Doutorado) - Faculdade de Medicina, USP, São Paulo. Estudo de caso sobre a implantação de propostas de humanização da assistência ao parto em maternidades de São Paulo, orientadas pelas noções de direitos e de medicina baseada na evidência científica. Foi usada metodologia qualitativa, com observação direta dos serviços em duas maternidades e análise documental. Os achados sugerem que, entre os fatores que podem tornar possíveis ou limitadas essas mudanças, estão a adequação do acesso a leitos, da comunicação entre os sujeitos, do manejo da dor e tempos no parto; e a presença de uma cultura de reconhecimento tanto da evidência científica quanto dos direitos das mulheres.

21. FERNANDEZ, Betânia M. "Representações femininas do parto normal e da cesárea". In: BRANDÃO, Elaine R. (Org.). Saúde, direitos reprodutivos e cidadania. Juiz de Fora: Editora da UFJF, 2000. p. 27-54. Pesquisa qualitativa realizada com 14 mulheres que se encontravam grávidas pela primeira vez, entre 18 e 35 anos, usuárias do Instituto de Saúde da Mulher. Nessa pesquisa buscou-se entender o sentido atribuído por mulheres das camadas populares ao parto normal e à cesárea como formas de resolução da gestação. (MLM)

22. FERREIRA, Maria M. As Caetanas vão a luta: um estudo sobre a trajetória do Grupo de Mulheres da Ilha e sua relação com as políticas públicas no Maranhão. 1999. Dissertação (Mestrado) - UFMA, São Luís. Nesse estudo a autora apresenta em um capítulo a contribuição desse Grupo na organização e articulação das parteiras, analisando seus limites e avanços e a importância das parteiras na relação com a saúde das mulheres.

23. FERREIRA, Maria M.; SANTOS, Marluze P. "Parteiras tradicionais: visibilidade e invisibilidade de um trabalho milenar". In: ALVARES, Maria Luzia M.; SANTOS, Eunice F.; D'INCAO, Maria Ângela (Orgs). Mulher e modernidade na Amazônia. Belém: CEJUP/GEPEM, 1997. 0 texto aborda a importância do trabalho das parteiras nas questões referentes à saúde das mulheres no Maranhão. Ressalta a atuação e contribuição do Grupo de Mulheres 
da llha na articulação e organização das parteiras e sua integração ao Sistema Único de Saúde.

24. FRAGA, Luiz Cláudio R. História oral e de vida de enfermeiros obstétricos. 1991. Dissertação (Mestrado) - Escola de Enfermagem Alfredo Pinto, UNIRIO, Rio de Janeiro.O estudo busca reconstruir a História da Enfermagem Obstétrica a partir de relatos orais de dez enfermeiras obstétricas e obstetrizes, formadas por diferentes escolas brasileiras.

25. FONSECA, Cláudia. Anatomia de uma maternidade: pesquisadores, profissionais de saúde e pacientes num quadro hospitalar. Relatório inédito. A pesquisa de campo foi realizada entre 1990 e 1991, nas maternidades públicas do Havre (França), tendo como objetivo analisar as modalidades de organização do espaço físico e social do parto em um quadro hospitalar moderno. Encomendada pelo Ministério da Saúde para uma 'etnóloga de plantão', para facilitar a comunicação entre médicos e parteiras (franceses) e parturientes africanas e árabes, a pesquisa acabou por se centrar nas diferentes formas de sociabilidade - entre membros da hierarquia funcional, entre esses funcionários e as parturientes (estrangeiras e francesas), e as usuárias. Foram consideradas as relações de gênero entre as parteiras (todas mulheres), médicos (todos, na época, homens) e pacientes, relações essas nas quais outros fatores como classe e nacionalidade vêm freqüentemente redefinir coalizões. Há, em particular, uma descrição da maioria esquecida de parturientes - as 'normandas' (francesas de origem modesta) - e suas reações às mudanças, e de novas filosofias (desde o parto sem dor até o enclausuramento do espaço) da maternidade.

26. FONSECA, Cláudia. "Quelques réflexions ethnologiques sur une maternité française". Ethnos (Association pour l'Anthropologie Médicale), LeHavre, França, 1992. Artigo baseado no relatório citado.

27. FONSECA, Cláudia. "Une mise en relief des valeurs de la médicine moderne". Cahiers de sociologie economique et culturelle, n. 23, p. 97-110, 1995. Artigo baseado no relatório citado.

28. FUSTIMONI, Suzete Maria. As necessidades de cuidado da parturiente: uma perspectiva compreensiva da Ação Social. 2000. Tese (Doutorado) - Escola de Enfermagem, USP, São Paulo. O estudo teve por objetivo desvelar o fenômeno da assistência às mulheres em trabalho de parto, sob a ótica de quem realiza a ação de assistir e de quem presta a assistência. Fundamenta-se no referencial teórico metodológico da Sociologia Fenomenológica de Alfredo Schultz, considerando que as pessoas expressam em suas ações socialmente vividas os significados dessas vivências. (MAT)

29. GARCIA, Teresinha Joana M. Formação em enfermagem obstétrica: perspectivas na Escola Paulista de Medicina. 1993. Tese (Doutorado) - Escola Paulista de Medicina, São Paulo. Estudo sobre a formação das/os enfermeiras/os obstetras, com destaque para o Curso de Enfermagem Obstétrica na Escola Paulista de Medicina (número de disciplinas, corpo docente e discente e produção acadêmica). (MLM)

30. GRUPO DE MULHERES DA ILHA. Parteiras e plantas. São Luís: Grupo de Mulheres da Ilha, 1991. Essa publicação é o resultado de uma pesquisa feita com as parteiras tradicionais na llha de São Luís (MA), com o objetivo de registrar os saberes e as práticas das parteiras no uso de plantas medicinais durante a gravidez, o parto e o pós-parto. (LS)

31. GRUPO DE MULHERES DA ILHA. Sacudindo a barriga. São Luís: Grupo de Mulheres da Ilha, 1995. Relatório do I Encontro Estadual de Parteiras Tradicionais do Maranhão. Nesse relatório estão expostos os resultados das oficinas, dados numéricos e perfil das participantes e as propostas apresentadas pelas parteiras na assembléia final do Encontro. (LS) 
32. GUALDA, Dulce Maria R. A experiência, o significado e a realidade da enfermeira obstetra: um estudo de caso. 1998. Tese (Livre-Docência) - Escola de Enfermagem, USP, São Paulo. Um estudo de caso etnográfico que teve como objetivo investigar o significado da vivência das enfermeiras nas unidades obstétricas do Hospital Universitário da Universidade de São Paulo. Foram realizadas entrevistas através das quais se verificou que se torna necessário o contato direto da profissional com as mulheres para identificar as necessidades individuais. A assistência de qualidade inclui habilidade técnica e sensibilidade ao longo do processo do nascimento, desde a gestação até o pós-parto. A satisfação é decorrente do confronto dos objetivos pessoais e profissionais da enfermeira obstétrica com a realidade assistencial. (MAT)

33. GUALDA, Dulce Maria R. "Eu conheço minha natureza": um estudo etnográfico da vivência do parto. 1993. Tese (Doutorado) - Escola de Enfermagem, USP, São Paulo. Esse estudo teve por objetivo conhecer o cuidado, as crenças, os valores e o significado atribuído à experiência do parto a partir da perspectiva de um grupo de mulheres faveladas. Foram utilizados a Teoria da Diversidade e Universalidade do Cuidado Cultural, de Leininger, e o método etnográfico. A coleta de dados foi feita por observação participante e entrevistas com mulheres que tiveram experiência anterior de parto hospitalar ou domiciliar. A natureza e a experiência constituíram o eixo de análise do processo do parto. (MAT)

34. HOGA Luiza Akiko K. Inovação da assistência e preservação da tradição: um olhar transcultural das Casas de Parto de São Paulo e de Osaka. 2001. Tese (Livre-Docência) - Escola de Enfermagem, USP, São Paulo. Trata-se de um estudo transcultural que teve como objetivo recuperar aspectos históricos e conjunturais relativos às Casas de Parto, e compreender e descrever as idéias, crenças e valores que guiavam as práticas das profissionais envolvidas com a assistência em uma Casa de Parto da cidade de São Paulo e em outra, da cidade de Osaka (Japão), identificando as similaridades e as diferenças existentes.

35. HOTIMSKY, Sonia N. Parto e nascimento no Ambulatório e na Casa de Partos da Associação Comunitária Monte Azul: uma abordagem antropológica. 2001. Dissertação (Mestrado) - Faculdade de Saúde Pública, USP, São Paulo. Esse estudo descreve o perfil da clientela de um serviço de parto ambulatorial, existente em São Paulo, entre 1983 e 1998, onde a assistência era prestada por obstetrizes, e discute os motivos que levaram mulheres de camadas populares e médias a buscar essa modalidade de atenção. No período entre 1995 e 1998, 93,5\% das 564 mulheres atendidas pertenciam aos estratos mais pobres da população do Município de São Paulo. Entre as razões apresentadas e que levaram à escolha desse serviço para realizarem o parto destacaram-se o relacionamento com profissionais de saúde, a percepção de riscos em relação ao parto e a possibilidade de contar com acompanhantes de sua escolha nesse evento. O maior temor das mulheres de camadas populares em relação ao parto hospitalar era o de não ter acesso a um leito, enquanto as mulheres de camadas médias temiam a cesárea desnecessária.

36. JARDIM, Rejane B. Revelando o implícito: irmãs de caridade e parteiras na formação do saber médico em Porto Alegre (1872-1940). 1998. Dissertação (Mestrado) - Instituto de Filosofia e Ciências Humanas, PUCRS, Porto Alegre. Esse estudo se refere à presença das mulheres no campo da medicina, aos saberes femininos sobre o corpo e ao conhecimento acerca da administração do hospital moderno. Procura compreender como ocorreu a articulação desses saberes com as formas modernas do conhecimento médico e o gerenciamento do espaço hospitalar. Analisa o espaço hospitalar da Santa Casa de Porto Alegre, os Cursos de Partos e de Medicina. Busca ainda discutir o papel 
das Irmãs de Caridade da Ordem Terceira de São Francisco de Heythuizem, no hospital da Santa Casa de Porto Alegre. (MLM)

37. JORGE, Dilce R. Evolução da legis/ação federal do ensino e do exercício profissional da obstetriz (parteira) no Brasil. 1975. Tese (Livre-Docência) - Escola de Enfermagem Anna Nery, UFRJ, Rio de Janeiro. Análise da legislação do exercício profissional das parteiras no Brasil desde o início da colonização portuguesa, da legislação federal do ensino de parteiras e dos principais cursos para formação de parteiras criados no Brasil nos séculos XIX e XX (tempo de duração, currículo, número de alunas). A tese foi elaborada a partir de pesquisa nos arquivos das várias escolas e inclui nos anexos vários documentos citados. (MLM)

38. LAMBERT, Ana Cláudia S. O acompanhamento da parturiente pela enfermeira obstétrica: estudo de caso das vivências das mulheres e das profissionais. 2001. Dissertação (Mestrado) - Escola de Enfermagem, USP, São Paulo. Trata-se de um estudo de caso sobre o acompanhamento do trabalho de parto e do parto feito por enfermeiras obstétricas. Os objetivos foram compreender e descrever as experiências tidas nesse processo por parte das puérperas e das profissionais. A experiência de ser acompanhada/acompanhar foi avaliada de forma positiva, tendo havido demonstração de satisfação, seja pelas puérperas, seja pelas profissionais

39. MARQUES, Rita de Cássia. "O início da medicalização do atendimento a saúde da mulher em Belo Horizonte". Revista Mineira de Enfermagem, v. 4, n. 1-2, p. 70-76, jan./ dez. 2000. História do atendimento à saúde da mulher, desde a fundação de Belo Horizonte, em 1987, até meados do século XX, privilegiando a ação dos primeiros médicos na obtenção de clientes, a desvalorização do trabalho das parteiras e a substituição do atendimento domiciliar pelo hospitalar.

40. MARTINI, Andréa. Tecendo limites na Foz do Breu, Acre, Brasil. 1998. Dissertação (Mestrado) - Instituto de Filosofia e Ciências Humanas, UNICAMP. Campinas. O objetivo desse trabalho é narrar a ocupação da fronteira brasileiro-peruana na vila Foz do Breu, Acre, área da Reserva Extrativista do Alto Juruá. Destaca-se a contribuição das mulheres para a conformação de redes sociais em dois 'sistemas territoriais' distintos. No capítulo IV - "Formas de Olhar Pessoas" - a autora relaciona categorias de pessoa, gênero e idade na manutenção dessas redes sociais. A experiência e trajetória da parteira veterana Ernestina Ferreira da Silva é tomada como exemplo. Nascida provavelmente em 1918 e falecida em junho de 2001 , ela partejou durante mais de 60 anos, sendo considerada 'parteira fina', nome atribuído na região àquelas que detêm informações e conhecimentos aprimorados por longos anos de experiência

41. MARTINS, Ana Paula V. "A ciência do feminino: a constituição da obstetrícia e da ginecologia". In: ADELMAN, Miriam; SILVESTRIN, Celsi B. (Org.). Gênero Plural. Curitiba: Editora da Universidade Federal do Paraná, 2002. O artigo analisa a constituição de um campo da medicina que tem por finalidade estudar o corpo feminino, composto por duas especialidades que, apesar de suas diferenças, acabam se sobrepondo: a obstetrícia e a ginecologia. O objetivo é explicar a especificidade da medicina do feminino no século XIX, como se constituiu e se legitimou enquanto especialidade médica, como definiu seu objeto, com quais categorias operava e quais teorias fundamentavam suas práticas, tomando com referência as questões problematizadas pela bibliografia mais recente sobre o tema.

42. MARTINS, Ana Paula V. A medicina da mulher: visões do corpo feminino na constituição da obstetrícia e da ginecologia no século XIX. 2001. Tese (Doutorado) - Instituto de Filosofia e Ciências Humanas, UNICAMP, Campinas. Esta tese tem como objetivo geral compreender como se deu a constituição de um campo discursivo voltado para a 
diferença sexual feminina. A pesquisa foi direcionada no sentido de desvendar o papel cultural da obstetrícia e da ginecologia na definição oitocentista da mulher, entender seu vocabulário, suas estratégias de objetivação e a força de suas verdades. Fez-se um inventário desses discursos, começando por aqueles produzidos na Europa, através da análise de tratados e manuais publicados desde a década de 1830 na França e na Inglaterra, por se constituírem no corpo principal do conhecimento sobre a mulher, sendo apropriados em outros locais de formação dos médicos, como as faculdades de medicina brasileiras. A tese também trata da constituição da medicina da mulher no Brasil, procurando entender como os médicos brasileiros se posicionaram no debate a respeito da natureza feminina, bem como das questões que os mobilizaram, como a defesa de um ensino que articulasse teoria e prática clínica, a criação de maternidades e uma ação mais efetiva do Estado na defesa da maternidade.

43. MELO, Célia Regina M. Mitos e realidade do parto: comparação do conhecimento e expectativas em dois grupos de primigestas. 2000. Dissertação (Mestrado) - Faculdade de Medicina, UNESP, Botucatu. O objetivo dessa dissertação é conhecer e descrever o perfil das amostras estudadas, comparando o conhecimento de dois grupos de primigestas, atendidas no serviço público e privado, sobre gestação, parto e puerpério, associando através das respostas obtidas a influência dos mitos sobre trabalho de parto e parto.

44. MENDONÇA, Lúcia $G$. A construção da imagem negativa das parteiras: uma análise comparativa dos casos brasileiro, britânico e norte-americano. Monografia em andamento como parte dos requisitos para a obtenção do título de Especialista na Universidade Estadual de Londrina. Esse trabalho é um estudo comparativo entre os casos brasileiro, britânico e norte americano da construção da imagem negativa das parteiras pelo discurso médico, durante o período de constituição do ensino formal da obstetrícia naquelas sociedades, particularmente concentrado no século XIX.Tem como objetivos: 1) situar o tema das parteiras na historiografia e sua relevância para os estudos históricos; 2) caracterizar os elementos particulares de cada sociedade no que diz respeito à atuação das parteiras e à construção da imagem negativa das mesmas, vistas como ignorantes e uma ameaça à saúde da população.

45. MENDONÇA, Lúcia G. Parteiras em Londrina: 1958-1995. Pesquisa em andamento em nível de Mestrado. Programa de Pós-Graduação em História das Ciências da Saúde Casa de Oswaldo Cruz, FIOCRUZ. Rio de Janeiro. A pesquisa busca entender a atuação das parteiras, a hospitalização do parto e a ampliação do sistema de atendimento à saúde da população em Londrina (PR) durante o período de intensificação do processo de urbanização da cidade. Através do relato das trajetórias de vida de parteiras tradicionais e diplomadas, assim como de suas clientes e de médicos que atuaram no mesmo período, pretende verificar qual o papel social desempenhado por essas mulheres na comunidade, na implantação e ampliação dos serviços de saúde em um contexto singular, o movimento dos médicos da cidade, representado pela Associação Médica local, pela livre escolha do médico pelo paciente e contra o sistema previdenciário de assistência médica.

46. MERIGHI, Miriam Aparecida B. Enfermeiras obstétricas egressas da Escola de Enfermagem da Universidade de São Paulo: caracterização e trajetória profissional. 2000. Tese (Livre-Docência) - Escola de Enfermagem, USP, São Paulo. Estudo realizado em dois momentos: 1) de caráter exploratório, que objetivou revelar as características das ex-alunas do curso de Enfermagem Obstétrica da EEUSP, no período de 1980 a 1995 ; 2) de caráter qualitativo, cujo objetivo foi compreender a experiência vivida pelas ex-alunas dos cursos de habilitação e especialização em Enfermagem Obstétrica 
na mesma Escola, utilizando o referencial teórico metodológico de sociologia fenomenológica de Schultz. Constatou-se que metade das ex-alunas atua na área. As que continuam na área gostam do que fazem e as que não atuam se decepcionaram, sentem-se frustradas, com falta de autonomia profissional. (MAT)

47. MOTT, Maria Lucia. "O curso de partos: deve ou não haver parteiras?" Cadernos de Pesquisa, n. 108, p. 133-160, nov. 1999. Analisa os cursos para formação de parteiras no século XIX. Levanta questões sobre perfil profissional, freqüência dos cursos e número de alunas matriculadas.

48. MOTT, Maria Lucia. "A parteira ignorante: um erro de diagnóstico médico?" Revista Estudos Feministas, v. 7, n. 1 , p. 25-36, 1999. O objetivo do artigo é discutir a construção da imagem da parteira ignorante elaborada por médicos brasileiros ao longo do século XIX e até mesmo por Mme Durocher, primeira parteira diplomada no Brasil. Através da análise de diferentes tipos de documentos (artigos, relatórios, teses, anúncios publicados na imprensa, requerimentos da Fisicatura-Mor, entre outros) estabelece um diálogo entre o discurso médico oficial e a prática das parteiras, apontando para a necessidade de se repensar o desgastado estereótipo.

49. MOTT, Maria Lucia. "Assistência ao parto: do domicílio ao hospital (1830-1960)". Revista Projeto História/PUCSP, número especial (Corpo e Cultura). No prelo. O artigo faz um retrospecto dos principais modelos de atendimento ao parto no país. Se até o início do século XX o parto era realizado no domicílio da parturiente, a partir dos anos 1930 os hospitais passam a ser recomendados de maneira veemente pelos médicos. Verificase então a fundação de várias maternidades e um aumento do número de leitos em hospitais, sobretudo para parturientes pagantes, sendo necessária a criação de novas formas de atendimento para as gestantes das camadas menos favorecidas, dada a carência de leitos gratuitos disponíveis. Organizam-se, assim, como solução emergencial, em alguns estados brasileiros, serviços obstétricos para atendimento domiciliar das mulheres pobres.

50. MOTT, Maria Lucia. "Fiscalização e formação das parteiras em São Paulo (1880-1920)". Revista de Enfermagem da USP, v. 13, n. 1, p. 46-43, mar. 2001. Esse artigo faz parte de uma pesquisa mais ampla realizada em nível de Pós-Doutorado na Escola de Enfermagem da USP (1999-2000), intitulada "Caminhos cruzados: os cursos para formação de parteiras e enfermeiras em São Paulo (1880-1971)", que teve por objetivo refletir sobre as atribuições de parteiras e enfermeiras obstétricas e a exclusão dessas profissionais na assistência ao parto no decorrer do século XX. O artigo se detém nos primeiros cursos para formação de parteiras e na fiscalização da profissão, apontando que no início do século XX já se pode perceber uma associação entre parteiras e enfermeiras, não apenas em alguns cursos para formação profissional, como também no cotidiano de trabalho. Passa a existir a expectativa de que a parteira fosse também enfermeira.

51. MOTT, Maria Lucia. "Mme Durocher: modista e parteira". Revista Estudos Feministas, v. 2, n. 3, p. 101-116,1994. O artigo se detém nos primeiros anos de Josefina Durocher no Brasil, na sua formação educacional, primeiro como modista, depois como parteira, fornecendo assim elementos para se pensar as possibilidades educacionais e profissionais do sexo feminino no Brasil no início do século XIX.

52. MOTT, Maria Lucia. "Parteiras no século XIX: Mme Durocher e sua época". In: COSTA, Albertina de O.; BRUSCHINI, Cristina (Org.). Entre a virtude e o pecado. Rio de Janeiro: Rosa dos Tempos; São Paulo: Fundação Carlos Chagas, 1992. p. 37-56. Primeiro texto publicado da autora sobre o tema. A partir da biografia da parteira franco-brasileira Mme Durocher, que exerceu a profissão no século XIX, e utilizando diferentes tipos de 
documentos, tais como os escritos deixados pela própria Mme Durocher e registros de parteiras feitos pela Fisicatura-Mor (1808-1828), analisa os diferentes tipos de parteiras que praticavam no Rio de Janeiro no referido período.

53. OSAVA, Ruth H. Assistência ao parto no Brasil: o lugar do não-médico. 1997. Tese (Doutorado) - Faculdade de Saúde Pública da USP, São Paulo. O estudo trata da participação de não-médicos na assistência ao parto, em particular, de enfermeiras obstétricas. Foi feita uma revisão histórica sobre: a participação masculina no parto a partir do século XVl; as disputas de parteiras e médicos nos Estados Unidos e na Inglaterra ao longo do século XIX; e a formação de parteiras no Brasil desde o século XIX até os dias atuais. Conclui que médicos e parteiras trabalham com paradigmas assistenciais opostos; os não-médicos poderiam garantir o espaço do parto humanizado e naturalizado, podendo melhorar substancialmente a assistência materna, reduzir custos e promover qualidade da experiência do nascimento e do parto. (MAT)

54. OSCAR, Luciene; PORTO, Fernando. A imagem institucional da Maternidade Leila Diniz de um grupo de acadêmicos bolsistas de Enfermagem. 2002. Monografia de conclusão de estágio pela Secretaria Municipal de Saúde do Rio de Janeiro, como acadêmica bolsista em Enfermagem - Maternidade Leila Diniz, Rio de Janeiro. Estudo de abordagem qualitativa sobre a imagem institucional da Maternidade Leila Diniz (MLD). Objetivos: identificar as representações acerca da imagem institucional e analisar os significados das representações, construindo uma realidade social. Metodologia: dinâmica de criatividade e sensibilidade (um mapa estilizado e 63 objetos aleatoriamente), que apontaram para a representação dos espaços do mapa da MLD e a grande selva: animais perdidos na selva e o desafio da sobrevivência.

55. PIMENTA, Tânia S. Artes de curar: um estudo dos documentos da Fisicatura-mor no Brasil no começo do século XIX. 1997. Dissertação (Mestrado) - Instituto de Filosofia e Ciências Humanas, UNICAMP, Campinas. Trabalho dividido em três capítulos. No primeiro faz-se referência à história da Fisicatura em Portugal e no Brasil (1808-1828). No segundo analisa-se a relação entre a instituição e as especialidades que possuíam mais status, os médicos, os cirurgiões e os boticários. No terceiro é enfatizada a relação da instituição, que privilegiava a concepção acadêmica de medicina, com grupos que exerciam as práticas de cura populares, tais como sangrar, partejar e curar, grupos esses formados por negros forros, mulheres, livres pobres. (MLM)

56. PINTO, Benedita Celeste M. "As guardiãs do ritual do nascimento". Revista Projeto História, n. 23. O artigo trata dos saberes e poderes mágicos com os quais parteiras e benzedeiras da região do Tocantins, no Pará, dominam técnicas de curas através de benzeções e poções feitas de ervas, raízes e cascas de paus vindas das matas e 'ribanceiras dos rios', com o que livram seu povo das doenças do plano natural e das ocasionadas pelas forças de encantarias.

57. PINTO, Benedita Celeste M. "Parteira curiosa: o dom de fazer vim ao mundo as pessoas". Revista Ágora Brasil, PUCSP, ano 2, n. 2, 1998. Esse estudo, baseado em relatos orais e em histórias de vida, trata dos saberes, poderes, manobras de partos e dos mundos de mistérios e encantarias das parteiras curiosas, no povoado negro rural de Umarizal, na região do Tocantins, no Pará.

58. PINTO, Benedita Celeste M. Nas veredas da sobrevivência: memória, gênero e símbolos de poder feminino em povoados amazônicos de antigos quilombolas. 1999. Dissertação (Mestrado) - Departamento de História, PUCSP, São Paulo. A pesquisa tem como problemática central o estudo das experiências históricas e as relações sociais de gênero. Analisa a construção da idéia de 'ausência' de 'fragilidade' e 'dependência' da mulher negra rural na região do Tocantins, no Pará. Destaca os diferentes papéis 
desempenhados pelas mulheres, entre eles o de parteira, no antigo quilombo do Paxibal e, posteriormente, no povoado oriundo deste, denominado Umarizal.

59. PINTO, Cleusa Maria S. Parto com acompanhante: a experiência dos profissionais. 2001. Dissertação (Mestrado) - Escola de Enfermagem, USP, São Paulo. A pesquisa teve o objetivo de compreender e descrever a experiência dos profissionais de saúde em relação à participação do acompanhante no parto e no nascimento. É um estudo qualitativo, desenvolvido em um hospital público vinculado à Secretaria de Estado da Saúde de São Paulo que permite a presença do acompanhante na assistência ao parto. Os profissionais tinham pouca prática com acompanhantes, e as primeiras experiências foram marcadas pela sensação de apreensão. Os acompanhantes possuíam atributos importantes que foram considerados pelos profissionais como fundamentais na assistência ao parto e produziam reflexos positivos em várias dimensões.

60. PORTO, Fernando; NASCIMENTO, Maria Aparecida L. O parto como notícia veiculada na mídia escrita: uma contribuição na discussão da polêmica sobre o enfermeiro obstetra realizar o parto. Inédito. Esse estudo analisa as manchetes sobre o parto veiculadas pela mídia escrita. O objetivo foi estudar o conteúdo à luz da bibliografia da comunicação - Técnicas de Argumentação. A metodologia partiu da seleção de 200 notícias (1974-1998) que estivessem diretamente relacionadas com o parto de ordem assistencial e/ou administrativa. Verificou-se que as denúncias de erros dos profissionais de saúde foram relatadas sem sensacionalismo, com fatos e apresentação de provas concretas de argumentação.

61. PORTO, Fernando; MORAES, Nilson Alves; NASCIMENTO, Maria Aparecida L. A cartografia de luta das enfermeiras obstetras na Maternidade Leila Diniz (1996-1998): do soldado ao batom... 2001. Dissertação (Mestrado) - Escola de Enfermagem Alfredo Pinto, UNIRIO. Os objetivos foram identificar representações da luta do Projeto de Assistência ao Parto e Nascimento na Maternidade Leila Diniz (MLD) e analisar os significados das representações, registrando sua memória. Metodologia: dinâmica de criatividade e sensibilidade (um mapa estilizado e 114 objetos aleatoriamente, do soldado ao batom), com duas categorias: A Cartografia do Espaço de Luta, com 11 territórios, e A Cartografia das Lutadoras: Guerreiras Feridas. A Morte Simbólica Durante a Luta, que resultou no registro de luta das enfermeiras obstetras na MLD.

62. PROGIANTI, Jane M.; BARREIRA, leda A. "A obstetrícia: do saber popular à medicalização". Revista de Enfermagem da UERJ, v. 9, n. 1, p. 91-97, 1. sem. 2001. O trabalho descreve as principais transformações da prática da obstetrícia e a participação feminina na construção desse saber. Dá ênfase ao saber popular, à obstetrícia brasileira e à consolidação da assistência hospitalar, mostrando a obstetrícia como um campo de lutas entre parteiras, médicos, parteiros e cirurgiões.

63. PROGIANTI, Jane M.; BARREIRA, leda A. "Parteiras, médicos e enfermeiras: a aquisição de habilidades profissionais na assistência à parturiente (Rio de Janeiro 1934/1949)". Revista de Enfermagem Escola Anna Nery, v. 5, n. 3, p. 307-314, dez. 2001. Esse estudo, de natureza histórico-social, tem como objeto de análise a aquisição de habilidades profissionais por parteiras, médicos e enfermeiras diplomadas na assistência à parturiente. Enfatiza as diferenças entre os habitus dos agentes e o modo de aquisição das habilidades profissionais nos diferentes cursos. Verifica que as diferentes disposições adquiridas na escola geraram práticas distintas, o que determinou a ocupação de diferentes espaços e posições pelos agentes no campo obstétrico.

64. PROGIANTI, Jane M. Parteiras, médicos e enfermeiras: a disputada arte de partejar (Rio de Janeiro-1934/1951). 2001. Tese (Doutorado) - Escola de Enfermagem Anna Nery, UFRJ, Rio de Janeiro. Estudo histórico-social que trata das lutas simbólicas travadas entre 
parteiras, médicos e enfermeiras diplomadas pela ocupação do espaço institucional de realização do parto durante o processo de medicalização da sociedade brasileira. Os resultados da pesquisa evidenciam que a parteira perdeu espaço e posição no campo obstétrico em relação à arte de partejar; o médico ganhou o monopólio do parto hospitalar e o controle do campo; e a enfermeira diplomada obteve uma vitória sobre a parteira com quem competia pelas posições administrativas na instituição hospitalar.

65. PROGIANTI, Jane M. "A trajetória feminina no campo obstétrico da cidade do Rio de Janeiro". Revista Enfermagem Atual, v. 2, ano 1, p. 9-12, mar./abr. 2001. Esse trabalho enfoca a trajetória do feminino no campo obstétrico da cidade do Rio de Janeiro, da colonização até 1934. Aborda a participação da parteira curiosa leiga, da parteira diplomada pelas escolas médicas e da enfermeira diplomada pelas escolas de enfermagem no campo obstétrico. Mostra o impacto da implantação da Escola de Enfermagem Anna Nery sobre o antigo modelo durocheriano.

66. RÉCHIA, Karen Christine. Lembranças íntimas de minha avó: partos, parteiras e outras histórias em Treze de Maio-SC. 1998. Dissertação (Mestrado) - UFSC, Florianópolis. Esse trabalho tem por objetivo dar visibilidade à prática cultural das parteiras, entre os anos 1930 e 1960, no município Treze de Maio (SC), bem como analisar a perda de espaço dessas profissionais na parturição, pela transferência do parto do domicílio para o hospital. Baseia-se em depoimentos orais (nove entrevistas ao todo, sendo uma parteira diplomada e uma parteira prática) e fontes impressas, com destaque para os jornais diários.

67. RIESCO, Maria Luiza G. Que parteira é essa? 1999. Tese (Doutorado) - Escola de Enfermagem, USP, São Paulo. Os objetivos foram: identificar quem é a parteira a que se referem os profissionais da área da saúde, quando defendem sua existência; e desvelar os pressupostos ideológicos que buscam justificar a formação dessa profissional. A 'parteira ideal' foi revelada sob duas perspectivas: de um lado é a parteira transitória que substitui o médico diante da carência de recursos; de outro, é sua antítese, a parteira de sempre, aquela que sempre existirá. A partir da superação dialética, da parteira ideal definida nos discursos, pode emergir a parteira possível, que é a 'parteira em construção', representando o projeto utópico, contra-hegemônico, capaz de romper com a taxionomia da profissão e com a visão ideologizada e desgenerificada da mulher diante dos seus direitos reprodutivos. (MAT)

68. RIESCO, Maria Luiza G. O preparo da gestante para o parto na formação da enfermeira obstetra. 1993. Dissertação (Mestrado) - Escola de Enfermagem, USP, São Paulo. Estudo de caso sobre o ensino-aprendizagem do preparo da gestante para o parto durante 0 Programa de Habilitação em Enfermagem Obstétrica da Escola de Enfermagem da Universidade de São Paulo, desenvolvido com nove alunas de 1991. Teve como objetivo descrever a experiência da participação no preparo para o parto na formação da enfermeira obstetra. São discutidas as categorias Trabalho em Grupo, Vínculo, Clientela, Temática e Experiência na Formação Profissional. (MAT)

69. SALÉM, Tania. "O ideário do parto sem dor: uma leitura antropológica". Boletim do Museu Nacional, n. 40, ago. 1983. O artigo faz uma leitura antropológica do Parto sem Dor, sobretudo nas ramificações surgidas nos anos 1970 e 1980, consideradas 'mais inovadoras' e 'mais modernas'. Discute questões como a psicologização da gravidez e do parto, e a mudança na rede de relações familiares implicadas nesses eventos, com destaque para a maior participação do pai. Ao contextualizar o ideário dentro de transformações sociais e ideológicas mais abrangentes, a análise redimensiona o caráter 'revolucionário' que os seguidores e divulgadores do movimento se auto-atribuem. Mais 
que isso: mostra como o ideário não apenas endossa valores sociais, mas, também, reflete dilemas fundamentais do período. (MLM)

70. SCAVONE, Lucila. 'As múltiplas faces da maternidade'. Cadernos de Pesquisa, n. 54, ago. 1985. O artigo baseia-se em pesquisa realizada em São Luis do Maranhão, nos anos de 1982 a 1984, com grupos de mulheres da periferia da cidade, tratando dos aspectos sociológicos da maternidade. Relacionando a maternidade com a saúde, destaca o trabalho das parteiras leigas nesse universo, suas práticas, rezas e crenças, repertoriando uma tradição cultural do parto em domicílio e sem medicalização. Embora as práticas das parteiras e dos partos domiciliares já não fossem majoritárias, no período pesquisado, elas ainda eram utilizadas e bem conhecidas por todas as mulheres das comunidades pesquisadas.

71. SILVA, Tânia Maria A. O saber dos médicos e o saber das parteiras: um estudo sobre a concepção do nascimento na sociedade brasileira. 1999. Dissertação (Mestrado) Instituto de Ciências Humanas e Sociais, Universidade Rural do Rio de Janeiro. O principal objetivo desse estudo foi interpretar a mudança dos saberes sobre o nascimento na sociedade brasileira. Partiu-se do pressuposto de que a passagem do saber das parteiras para o saber dos médicos, assentado sobre a visão da ciência moderna, faz parte de um contexto histórico amplo, com raízes na Revolução Científica européia e na ideologia burguesa. As mudanças e permanências no campo dos saberes sobre o nascimento, no Brasil, relacionam-se à divulgação e à incorporação, em maior ou menor escala, de determinadas idéias e conceitos a respeito de atraso e modernidade. Inicialmente, o modelo científico, seguido pelos médicos brasileiros, baseava-se na visão médicocientífica européia e, posteriormente, na americana.

72. SOARES, Francisca N. A enfermeira obstétrica: sua função em sala de parto. 1972. Tese (Doutorado) - Escola de Enfermagem, USP, São Paulo. Pesquisa realizada em hospitais assistenciais em São Paulo, com o objetivo de verificar quais funções os médicos e as enfermeiras obstétricas estavam exercendo em cada fase do trabalho em sala de parto e quais funções esses profissionais acreditavam que deveriam exercer. Analisa as conseqüências da falta de conhecimento adequado da atuação da enfermeira obstétrica no seu campo de atuação.

73. TORNQUIST, Carmen Susana. "A mão e luva: o processo de medicalização do parto e o corpo feminino". In: MORGA, Antonio (Org.). História das mulheres de Santa Catarina. Florianópolis: Argos/Letras Contemporâneas, 2000. O artigo traz os resultados de uma pesquisa qualitativa, articulando recursos etnográficos com história oral, reconstruindo histórias de parteiras e de partos na llha de Santa Catarina, região cujo processo de medicalização do parto foi tardio em relação a outras capitais do Sul do país. Nesses relatos procurou-se compreender o universo simbólico das mulheres acerca do parto e de seus corpos, e como se deu o processo de migração das parturientes da casa para o hospital. Observou-se que esse processo, cujo apogeu se deu na década de 1960, foi vitorioso - menos em função da adesão das mulheres das classes populares a um modelo medicalizado do que das relações de poder entre a medicina, representada pelas parteiras formadas pelos cursos de partos que passaram a atuar nas maternidades de Santa Catarina, e as práticas e saberes populares das parteiras tradicionais.

74. TORNQUIST, Carmen Susana. Análise do movimento de humanização do parto e do nascimento no Brasil. Projeto de Tese de Doutorado. Antropologia Social, UFSC, Florianópolis, 2001. O trabalho se propõe a refletir sobre alguns pontos do emergente ideário da humanização do parto e do nascimento, que tem se concretizado a partir de diversas ações sociais e políticas visando a modificações na assistência ao parto e ao nascimento no Brasil, notadamente aquelas que envolvem a saúde coletiva. Analisa 
algumas das noções centrais desse ideário, como as noções de parto natural e humanização, as noções de natureza e instinto materno e a idéia de empoderamento das mulheres através da modificação da assistência ao parto.

75. TSUNECHIRO, Maria Alice. A formação da enfermeira obstétrica no Estado de São Paulo. 1987. Tese (Doutorado) - Escola de Enfermagem, USP, São Paulo. Trata-se de estudo qualitativo cujo objetivo foi analisar a formação da enfermeira obstétrica no Estado de São Paulo. Foram entrevistadas 18 professoras e 12 egressas de oito escolas de enfermagem do Estado que ofereceram a Habilitação em Enfermagem Obstétrica em 1984 e 1985. O estudo revelou que a formação da enfermeira obstétrica, de modo geral, é pouco satisfatória, centrada na assistência à parturiente e ao parto, e que essa formação atende precariamente às expectativas das ex-alunas e às aspirações das professoras.

76. VIEIRA, Elizabeth M. "A medicalização do corpo feminino". In: Giffin, K.; Costa S.H. (Orgs.). Questões de saúde reprodutiva. Rio de Janeiro: Editora FIOCRUZ, 1999. p. 67-78. O artigo recupera a história da medicalização do corpo feminino e a assistência médica à mulher e ao parto a partir de idéias vigentes no século XIX. Discute a idéia de natureza feminina e aborda o desenvolvimento da obstetrícia nas escolas médicas apontando as dificuldades de transformar o parto em um evento médico. A medicalização do corpo feminino também é abordada ao se discutir a assistência médica à mulher e a medicalização da anticoncepção.

\section{Bibliography on Birth Assistance in Brazil (1972-2002)}

Abstract: The organization of this bibliography aimed at 1) publishing studies on birth assistency in Brazil, produced in different fields of knowledge (history, anthropology, nursing, medicine, social assistance, psychology, and sociology, 2) bringing researchers - on the into contact and 3) opening space for subjects, approaches and authors not included in the Dossier. The list references and summarizes 76 works (papers, theses, dissertations, reports, primers) by about 50 authors, published or produced between 1972 and 2002.

Key words: birth assistency, bibliography, Brazil (1972-2002). 